\title{
RESTING CORONARY FLOW AND CORONARY FLOW RESERVE IN HUMAN INFANTS AFTER REPAIR OR PALLIATION OF CONGENITAL HEART DEFECTS AS MEASURED BY POSITRON EMISSION TOMOGRAPHY
}

Jon P. Donnelly, MD

David M. Raffel, PhD

Barry L. Shulkin, MD

James R. Corbett, MD

Edward L. Bove, MD

Ralph S. Mosca, MD

Thomas J. Kulik, MD

\begin{abstract}
Objective: Coronary physiology in infants with congenital heart disease remains unclear. Our objective was to better understand coronary physiology in infants with congenital heart disease. Methods: We used positron emission tomography with nitrogen 13-labeled ammonia to measure myocardial perfusion at rest and with adenosine $(142 \mu \mathrm{g} / \mathrm{kg} / \mathrm{min} \times 6$ minutes $)$ in five infants after anatomic repair of a congenital heart lesion (group I), and in five infants after Norwood palliation for hypoplastic left heart syndrome (group II). The groups were matched for age, weight, and time from the operation. Results: Resting coronary flow in the left ventricle in group I was $1.8 \pm 0.2 \mathrm{ml} / \mathrm{min} / \mathrm{gm}$; resting flow in the right ventricle in group II was $1.0 \pm 0.3 \mathrm{ml} / \mathrm{min} / \mathrm{gm}(p=\mathbf{0 . 0 0 3})$. Coronary flow with adenosine was $2.6 \pm 0.5 \mathrm{ml} / \mathrm{min} / \mathrm{gm}$ in group I and $1.5 \pm 0.7 \mathrm{ml} / \mathrm{min} / \mathrm{gm}$ in group II $(p=$ 0.02). Absolute coronary flow reserve was the same in both groups (1.5 \pm 0.2 in group I vs $1.6 \pm 0.3$ in group II, $p=0.45)$. Oxygen delivery was reduced in group II compared with group I at rest $(16.1 \pm 4.2 \mathrm{ml} / \mathrm{min} / 100$ gm vs $28.9 \pm 4.42 \mathrm{ml} / \mathrm{min} / 100 \mathrm{gm}, p=0.02)$ and with adenosine $(25.5 \pm 8.1$ $\mathrm{ml} / \mathrm{min} / 100 \mathrm{gm}$ vs $42.3 \pm 5.8 \mathrm{ml} / \mathrm{min} / 100 \mathrm{gm}, p=0.02)$. Conclusions: Infants with repaired heart disease have higher resting flow and less coronary flow reserve than previously reported for adults. After Norwood palliation, infants have less perfusion and oxygen delivery to the systemic ventricle than do infants with a repaired lesion. This may in part explain why the outcome for patients with Norwood palliation is less favorable than for others. (J Thorac Cardiovasc Surg 1998;115:103-10)
\end{abstract}

$T^{\prime}$ he heart has an inordinately high rate of oxygen consumption compared with other, less metabolically active organs. Adequate oxygen is supplied to the myocardium under varying physiologic conditions through regulation of coronary artery flow. The extent to which coronary blood flow can be increased above resting flow, as is seen during reactive hyperemia or

Department of Pediatrics, Division of Pediatric Cardiology; Department of Surgery, Division of Pediatric Cardiovascular Surgery; and Department of Internal Medicine, Division of Nuclear Medicine; University of Michigan, Ann Arbor, Mich.

Supported by funds from the National Institutes of Health through a grant from the Clinical Research Center at the University of Michigan Medical Center.

Received for publication March 25, 1997; revisions requested July 8, 1997; revisions received July 30, 1997; accepted for publication August 8, 1997.

Address for reprints: Thomas J. Kulik, MD, University of Michigan Hospitals, MCHC F1310, Box 0204, Ann Arbor, MI 48109-0204.

Copyright (C) 1998 by Mosby, Inc.

$0022-5223 / 98 \$ 5.00+0 \quad \mathbf{1 2} / \mathbf{1} / \mathbf{8 5 3 7 1}$ adenosine infusion, is termed coronary flow reserve. ${ }^{1}$ Coronary flow reserve is commonly expressed as coronary flow during maximal coronary vasodilatation divided by resting flow. ${ }^{2,3}$ In the adult human heart, left ventricular myocardial perfusion can be increased fourfold relative to resting perfusion with maximal coronary dilatation. ${ }^{4,5}$ Little is known about myocardial perfusion in the infant heart, although studies performed in late-gestation fetuses and newborn lambs suggest that infants have a coronary flow at rest that is twice the adult value. ${ }^{6}$ The degree to which neonates can increase myocardial blood flow with maximal coronary dilatation is unknown, and there are no published reports quantifying coronary flow or coronary flow reserve in human infants.

Infants with certain types of structural heart disease may be at risk for diminished resting flow or coronary flow reserve, and this may become clinically important when myocardial oxygen demand increases acutely. Infants with hypoplastic left heart system (HLHS) after Norwood palliation may be at 
A.

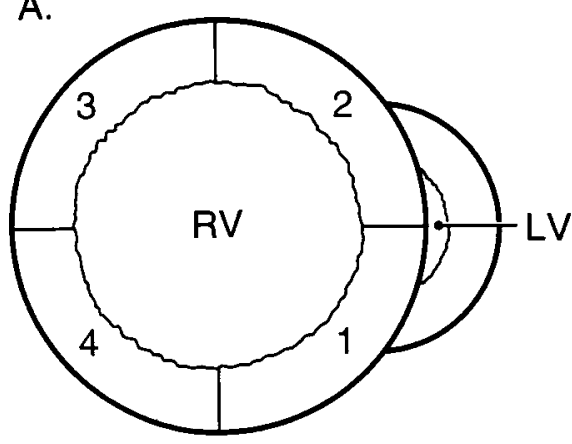

Inf-sept (1)

Ant-sept (2)

Ant-lat (3)

Inf-lat (4)
B.

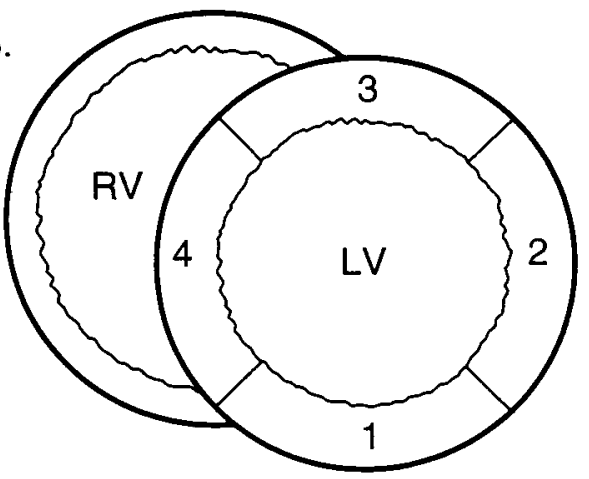

Inferior (1)
Lateral (2)
Anterior (3)
Septal (4)

Fig. 1. ROIs within the systemic ventricular wall for (A) infants with HLHS after Norwood palliation (group II), and (B) infants with repaired structural heart disease (group I). $R V$, Right ventricle; $L V$, left ventricle; Inf-sept, inferoseptal; Ant-sept, anteroseptal; Ant-lat, anterolateral; Inf-lat, inferolateral.

particularly high risk for coronary insufficiency. There is a large diastolic runoff from the neoaorta into the pulmonary arteries through the modified Blalock-Taussig shunt, creating diminished diastolic perfusion pressure for the coronary circulation. Oxygen consumption is increased in the volume- and pressure-loaded right ventricle. There is a potential for proximal coronary artery constriction as a result of the technically complex neoaortic reconstruction.

This study used positron emission tomography (PET) to measure resting coronary flow and coronary flow reserve in human infants who had anatomic repair of a congenital heart lesion. The data were used to determine whether infants with HLHS after Norwood palliation have altered myocardial perfusion or coronary flow reserve compared with those with completely repaired congenital cardiac defects.

\section{Methods}

Subjects. Group I subjects were five infants who underwent complete surgical repair of structural heart defects that are not thought to be associated with limited myocardial perfusion (Table I). Group II consisted of five infants with HLHS who underwent stage-one palliation within the first 17 days after birth. Each of these infants received a $3.5 \mathrm{~mm}$ modified Blalock-Taussig shunt from the right innominate artery to the pulmonary artery bifurcation as part of their operative procedure. ${ }^{7}$ The diagnosis of HLHS was made by transthoracic echocardiography and was defined as mitral and aortic hypoplasia or atresia in the presence of a non-apex-forming left ventricle. All group II patients had the echocardiographic diagnosis of HLHS made in utero or soon after birth, so that ductal patency was maintained with prostaglandin $E_{1}$ and no patient had been in hemodynamically unstable condition before the operation. Likewise, group I patients had diagnosis by transthoracic echocardiography in the neonatal period and were in hemodynamically stable condition before the operation. Postoperative echocardiograms revealed all but one patient to be free of residual lesions (one of the group II patients had moderate tricuspid regurgitation). Both groups were in clinically stable condition and doing well when they were studied. Two of five group I patients and three of five group II patients were receiving maintenance digoxin therapy when they were studied. No patient was receiving mechanical ventilation or intravenous inotropic or vasoactive support when studied. Patient selection was driven primarily by parental willingness for their child to participate and availability of the PET scanner. Although the patients were not chosen randomly from among all those undergoing similar operations at our institution, we consider them representative of this population. The protocol was approved by the Institutional Review Board and the Subcommittee for the Use of Radioisotopes in Human Subjects at the University of Michigan. The parents of each patient gave written and informed consent before enrollment in the study.

Adenosine infusion. To measure coronary flow reserve, the infants received a continuous intravenous infusion of adenosine (Adenocard, Fujisawa USA, Deerfield, Ill.) at a dose of $142 / \mu \mathrm{g} / \mathrm{kg} / \mathrm{min}$ for 6 minutes. Previous doseresponse testing in adults has determined this to be the lowest dose that provides maximal coronary dilatation and myocardial perfusion. ${ }^{8}$ Although continuous adenosine infusions have been administered to adults for the treatment of pulmonary hypertension, $, 9,10$ there are no re- 
Table I. Patient characteristics

\begin{tabular}{cllccccc}
\hline Patient & Diagnosis & Sex & Age (days) & Weight (kg) & Postop (days) & $H b$ & $\mathrm{O}_{2}$ Sat \\
\hline Group I & & & & & & & \\
1 & VSD & F & 89 & 2.79 & 10 & 14.1 & 95 \\
2 & PA/VSD & M & 9 & 3.26 & 7 & 11.8 & 89 \\
3 & Discont. PAs & F & 46 & 3.47 & 5 & 14.3 & 94 \\
4 & IAA/VSD & M & 23 & 3.17 & 11 & 11.0 & 92 \\
5 & D-TGA & M & 27 & 3.15 & 13 & 13.4 & 98 \\
Mean \pm SD & & & $38.8 \pm 31.0$ & $3.17 \pm 0.24$ & $9.2 \pm 3.2$ & $12.9 \pm 1.4$ & $93.6 \pm 3.4$ \\
Group II & & & & & & \\
1 & HLHS (MA) & F & 16 & 3.43 & 9 & 15.2 & 76 \\
2 & HLHS (MA) & F & 26 & 3.79 & 15 & 17.1 & 82 \\
3 & HLHS (MH) & M & 26 & 3.35 & 9 & 16.8 & 72 \\
4 & HLHS (MA) & M & 18 & 3.89 & 11 & 17.2 & 83 \\
5 & HLHS (MH) & M & 26 & 3.20 & 22 & 14.0 & 77 \\
Mean \pm SD & & & $22.4 \pm 5.0$ & $3.53 \pm 0.30$ & $13.2 \pm 5.5$ & $16.1 \pm 1.4$ & $78.0 \pm 4.5$ \\
$p$ Value & & & 0.28 & 0.07 & 0.20 & 0.008 & 0.0003 \\
\hline
\end{tabular}

$H b$, Blood hemoglobin; $\mathrm{O}_{2}$ Sat, systemic arterial oxygen saturation; $V S D$, ventricular septal defect; $P A / V S D$, pulmonary atresia with ventricular septal defect; Discont $P A s$, discontinuous pulmonary arteries; $I A A / V S D$, interrupted aortic arch with a ventricular septal defect; $D-T G A$, dextrotransposition of the great arteries; $S D$, standard deviation; $M A$, mitral atresia; $M H$, mitral hypoplasia; Postop, time after the operation that the PET study was performed.

ported cases of continuous adenosine infusions in infants. We therefore administered a test infusion 1 day before the study while the infants were closely monitored in an intensive care setting to ensure that the medication would be tolerated. Heart rate, blood pressure, and oxygen saturations were measured at baseline and throughout the infusion.

PET. All patients received chloral hydrate $(100 \mathrm{mg} / \mathrm{kg}$ orally) before being transported to the PET scanning suite. Patients were spontaneously breathing and asleep before being placed within the PET camera (Siemens CTI 931; Siemens, Knoxville, Tenn.) with the heart centered in the middle of the field of view. A brief transmission scan was performed for attenuation correction before injection of $4 \mathrm{mCi}$ nitrogen 13-labeled ammonia intravenously during 30 seconds.

Images were then acquired dynamically for 15 minutes. Approximately 45 minutes later, after decay of the nitrogen 13 activity, patients underwent adenosine infusion to determine maximal coronary flow. Three minutes after the start of the infusion, the subjects received $4 \mathrm{mCi}$ nitrogen 13-labeled ammonia intravenously during 30 seconds. The adenosine infusion was continued for a total of 6 minutes, and images were repeated.

Myocardial flow was measured in 16 ventricular regions. The ventricular wall was divided into four regions of interest (ROIs) in four contiguous, short-axis slices covering the distal and proximal regions of the ventricle (Fig. 1). For each ROI, time-activity data were generated for compartmental modeling of the nitrogen 13-labeled ammonia kinetics. The time-activity curves were fit into a three-compartment model for quantification of regional and global myocardial flow as previously described elsewhere. ${ }^{11,12}$ All flows are expressed in milliliters per minute per gram of tissue. Only flow to the systemic ventricle (left ventricle in group I and right ventricle in group II) was measured and analyzed for comparison. Group I infants had minimal retention of nitrogen 13labeled ammonia within their right ventricular myocar- dium, making it difficult to distinguish myocardial flow from the tracer found within the blood pool. Consequently, the morphologically right ventricles could not be compared between groups.

Regional flows were compared for each group at rest and during an adenosine infusion to determine whether flows are preferentially distributed during adenosine hyperemia. The left ventricles of group I patients were divided into regions designated as inferior, lateral, anterior, and septal. The systemic right ventricles of group II patients were divided into four ROIs with the following designations: anteroseptal, anterolateral, inferoseptal, and inferolateral, with septal referring to the right ventricular myocardium separating the right ventricular cavity from the hypoplastic left ventricular chamber (Fig. 1).

Oxygen delivery to the myocardial tissue was calculated for both groups by multiplying the oxygen content of the blood (milliliters of oxygen per liter of blood) by the flow (milliliters per minute per $100 \mathrm{gm}$ of tissue) and is expressed in milliliters per minute per $100 \mathrm{gm}$ of tissue. Oxygen carrying capacity was calculated by multiplying each patient's hemoglobin level (measured within 24 hours of the study) by the oxygen carrying capacity of $1 \mathrm{gm}$ hemoglobin $(13.6 \mathrm{ml} / \mathrm{L})$. The oxygen saturation measured during the resting portion of the PET scan (with a Nellcor pulse oximeter, Nellcor, Inc., Hayward, Calif.) was multiplied by the oxygen carrying capacity to determine oxygen content.

Statistical analysis. Global myocardial flows between groups were compared with an unpaired Student's $t$ test. When reporting regional flows, values for each of the four contiguous slices were averaged within each ROI. Mean regional flows at rest were then compared with those during adenosine for patients within groups by means of a paired $t$ test. For comparisons of hemodynamic data, Student's $t$ tests were computed to compare groups at each time during the adenosine infusion, comparisons between each subsequent time and baseline were computed within each group separately by means of paired $t$ 
A

REST

STRESS

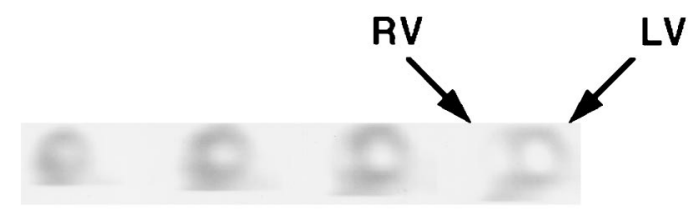

REST

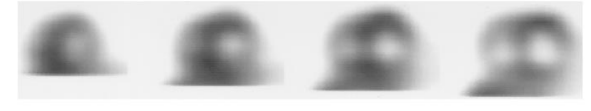

B

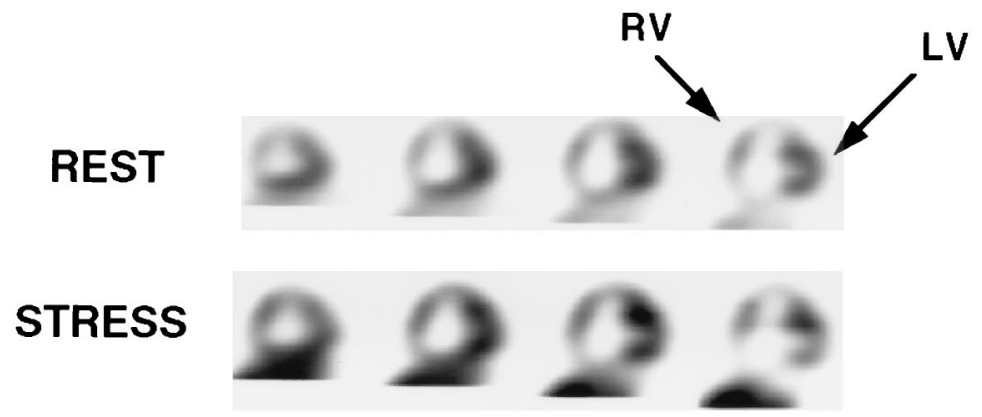

Fig. 2. Examples of four contiguous, short-axis images of myocardial nitrogen 13-labeled ammonia uptake at rest (upper row) and during adenosine infusion (stress) in (A) a patient with dextrotransposition of the great arteries after an arterial switch operation and (B) a patient with HLHS after Norwood palliation. Images are displayed from the apex to the base of the heart. Note the intense signal within the hypoplastic left-ventricle in B. $L V$, Left ventricle; $R V$, right ventricle.

tests, and overall analyses to assess both group and time variations simultaneously were computed by means of the two-factor analysis of variance for repeated measures (profile analysis).

\section{Results}

Adenosine infusion. All patients tolerated both the trial infusion of adenosine and the adenosine infusion during the PET scan without difficulty. Mean systolic blood pressures fell during the adenosine infusion by $16 \%$ in group I (77 vs $65 \mathrm{~mm} \mathrm{Hg}$; $p=0.03$ ) and $13 \%$ in group II (78 vs $68 \mathrm{~mm} \mathrm{Hg} ; p=$ 0.07 ) and mean diastolic blood pressures fell by $24 \%$ in group I (49 vs $37 \mathrm{~mm} \mathrm{Hg} ; p=0.004$ ) and $14 \%$ in group II ( 36 vs $31 \mathrm{~mm} \mathrm{Hg} ; p=0.19$ ). The mean heart rate increased by $16 \%$ in group I (128 vs 149 beats/min; $p=0.003$ ) and 8\% in group II (130 vs 141 beats $/ \mathrm{min} ; p=0.03$ ) during the adenosine infusion. There was no difference in systolic blood pressure or heart rate between groups at baseline or at any time during the infusion. Group II infants had significantly lower diastolic blood pressures at baseline than did group I infants, which probably reflects the diastolic runoff through the Blalock-Taussig shunt $(p=0.02)$. Both groups had a drop in diastolic blood pressure during adenosine infusion, with significant differences between groups occurring during the first half of the infusion. After 3 minutes, infants in group I had diastolic pressures similar to those in group II. Diastolic blood pressures returned to baseline in both groups within 3 minutes of discontinuation of the adenosine and were again lower in the group II infants $(p=0.07)$.

Coronary flow and flow reserve. Fig. 2 demonstrates the myocardial uptake of nitrogen 13-labeled ammonia at rest and during the adenosine infusion in one patient from each group. Flow to the systemic right ventricle of group II infants was significantly increased compared with flow to the pulmonary 
Table II. Myocardial flow and oxygen delivery to the systemic ventricle

\begin{tabular}{|c|c|c|c|c|c|}
\hline \multirow[b]{2}{*}{ Patient } & \multicolumn{3}{|c|}{ Myocardial flow (ml/min/gm) } & \multicolumn{2}{|c|}{ Oxygen delivery $(\mathrm{ml} / \mathrm{min} / 100 \mathrm{gm})$} \\
\hline & Rest & *Stress & Reserve & Rest & *Stress \\
\hline \multicolumn{6}{|l|}{ Group I } \\
\hline 1 & $1.40 \pm 0.42$ & $2.10 \pm 0.29$ & $1.59 \pm 0.37$ & 25.50 & 38.25 \\
\hline 2 & $1.82 \pm 0.75$ & $2.60 \pm 0.70$ & $1.52 \pm 0.26$ & 25.99 & 37.14 \\
\hline 3 & $1.84 \pm 0.70$ & $2.40 \pm 1.03$ & $1.30 \pm 0.23$ & 33.27 & 43.87 \\
\hline 4 & $1.85 \pm 0.34$ & $2.41 \pm 0.71$ & $1.29 \pm 0.22$ & 25.46 & 33.17 \\
\hline 5 & $1.91 \pm 0.70$ & $3.30 \pm 1.77$ & $1.67 \pm 0.63$ & 34.11 & 58.94 \\
\hline Mean \pm SD & $1.76 \pm 0.19$ & $2.56 \pm 0.41$ & $1.47 \pm 0.15$ & $28.87 \pm 3.98$ & $42.27 \pm 9.07$ \\
\hline $\mathrm{Cl}_{90}$ & $1.58-1.95$ & $2.16-2.97$ & $1.32-1.63$ & $24.88-32.85$ & $33.20-51.35$ \\
\hline \multicolumn{6}{|l|}{ Group II } \\
\hline 1 & $0.67 \pm 0.17$ & $1.34 \pm 0.28$ & $2.04 \pm 0.30$ & 10.53 & 21.05 \\
\hline 2 & $0.88 \pm 0.28$ & $1.37 \pm 0.29$ & $1.57 \pm 0.53$ & 16.78 & 26.12 \\
\hline 3 & $0.94 \pm 0.20$ & $1.26 \pm 0.47$ & $1.32 \pm 0.38$ & 15.46 & 20.72 \\
\hline 4 & $0.79 \pm 0.14$ & $1.03 \pm 0.23$ & $1.31 \pm 0.25$ & 15.34 & 20.00 \\
\hline 5 & $1.51 \pm 0.22$ & $2.69 \pm 0.69$ & $1.77 \pm 0.28$ & 22.14 & 39.44 \\
\hline Mean \pm SD & $0.96 \pm 0.29$ & $1.54 \pm 0.59$ & $1.60 \pm 0.28$ & $16.05 \pm 3.74$ & $25.47 \pm 7.37$ \\
\hline $\mathrm{CI}_{90}$ & $0.66-1.25$ & $0.95-2.13$ & $1.32-1.88$ & $12.31-19.79$ & $18.03-32.84$ \\
\hline$p$ Value & 0.003 & 0.02 & 0.45 & 0.02 & 0.02 \\
\hline
\end{tabular}

$S D$, Standard deviation; $C I_{90}, 90 \%$ confidence interval.

*Stress represents values obtained during adenosine infusion at $142 \mu \mathrm{g} / \mathrm{kg} / \mathrm{min} ; p$ values represent group I vs group II.

right ventricle of group I infants (although the small amount of tracer uptake in the latter did not permit quantitative comparison).

Group II infants had significantly less flow to their systemic (right) ventricle at rest than did group I infants $(p=0.003)$. Measured flows during adenosine infusion were also greater in group I $(p=0.02)$, although the percentage increases were similar, so that coronary flow reserve was not statistically different ( $p=0.45$; Table II). When oxygen delivery to the systemic ventricle was compared between groups, group II infants had significantly less delivered oxygen per $100 \mathrm{gm}$ tissue than did group I infants, both at rest $(p=0.002)$ and during adenosine hyperemia ( $p=0.02$; Table II).

When regional flows were analyzed for each group (Table III), group I infants had greater flow to the lateral region of their left ventricle at rest $(p=$ 0.01 ), with all other regions being similar between groups. During adenosine hyperemia, the lateral region again received significantly more flow than did all other regions $(p=0.04)$ except the anterior region $(p=0.08)$. There was therefore no difference in calculated coronary flow reserve among regions in group I. Group II infants had preferential flow to the septal regions of the right ventricle at rest ( $p=$ 0.01 vs lateral regions). During stress, greater increases in flow were seen in the lateral regions, so there were no regional differences in myocardial flow with adenosine hyperemia. Coronary flow re- serve was calculated to be significantly higher in the anterolateral region ( $p \leq 0.04$ vs septal regions), whereas the mean reserve in the inferolateral region was similar to those in the septal regions.

\section{Discussion}

Coronary flow has been difficult to study in human infants because of the lack of a reliable and noninvasive means of measuring myocardial perfusion. PET, however, has become an experimentally validated and clinically accepted method of measuring coronary flow in adults..$^{2-5,13} \mathrm{We}$ therefore used this modality to investigate coronary flow and flow reserve in the human infant. Our findings indicate that PET provides technically acceptable imaging of myocardial perfusion in the human infant despite the small size of the heart. The application of this technique to the human infant allows, for the first time, accurate quantitation of myocardial perfusion in this group of patients.

PET quantitation of resting myocardial perfusion in group I infants $(1.8 \pm 0.2 \mathrm{ml} / \mathrm{min} / \mathrm{gm})$ was higher than that measured by Chan and colleagues ${ }^{4}$ in healthy, adult volunteers $(1.1 \pm 0.2 \mathrm{ml} / \mathrm{min} / \mathrm{gm}, n=$ $20, p=0.0003)$. Higher coronary flow at rest in infants is consistent with data from experiments performed in sheep. ${ }^{6}$ Moreover, neonates have higher heart rates and metabolic rates than do adults, both of which would predispose them toward higher coronary flows at rest. ${ }^{14}$ Maximal myocardial 
Table III. Mean regional myocardial flow to the systemic ventricle

\begin{tabular}{|c|c|c|c|c|c|c|c|c|}
\hline & \multicolumn{4}{|c|}{ Rest $(\mathrm{ml} / \mathrm{min} / \mathrm{gm})$} & \multicolumn{4}{|c|}{ Stress* $(\mathrm{ml} / \mathrm{min} / \mathrm{gm})$} \\
\hline & 1 & 2 & 3 & 4 & 1 & 2 & 3 & 4 \\
\hline Group I & $1.39 \pm 0.44$ & $1.87 \pm 0.43$ & $1.38 \pm 0.46$ & $1.09 \pm 0.43$ & $2.02 \pm 0.54$ & $2.29 \pm 0.48$ & $2.05 \pm 0.28$ & $1.67 \pm 0.40$ \\
\hline Group II & $1.04 \pm 0.27$ & $1.04 \pm 0.16$ & $0.85 \pm 0.21$ & $0.94 \pm 0.29$ & $1.52 \pm 0.54$ & $1.67 \pm 0.25$ & $1.63 \pm 0.31$ & $1.55 \pm 0.80$ \\
\hline
\end{tabular}

Regions are as follows: 1, Inferior in group I and inferoseptal in group II; 2, lateral in group I and anteroseptal in group II; 3, anterior in group I and anterolateral in group II; 4, septal in group I and inferolateral in group II.

*Stress represents values obtained during adenosine infusion at $142 \mu \mathrm{g} / \mathrm{kg} / \mathrm{min} ; p$ values represent group I vs group II.

perfusion in group I infants $(2.6 \pm 0.5 \mathrm{ml} / \mathrm{min} / \mathrm{gm})$ was significantly less than that found in adults $(4.4 \pm$ $0.9 \mathrm{ml} / \mathrm{min} / \mathrm{gm})$, as determined with identical adenosine dosing and imaging techniques $(p<0.0001)$. Group I patients therefore had a coronary flow reserve only $37 \%$ that of adults, suggesting that infants may be less able to maximally increase myocardial blood flow at times of increased oxygen demand. There are, however, several factors that need to be taken into account when interpreting these data.

First, group I patients were not truly healthy; they had structurally abnormal hearts at birth. However, they all underwent complete surgical repair and had no echocardiographic or clinical evidence of altered hemodynamics at the time that they were studied. In addition, neither the original cardiac lesion nor the surgical repair should cause myocardial perfusion to differ in these patients from that in infants with normal cardiac anatomy at birth. Three of the control infants had a ventricular septal defect repaired with a polytetrafluoroethylene (PTFE) patch, ${ }^{*}$ resulting in relatively less perfusable septal myocardium. Because the defects were located high in the ventricular septum, however, it is unlikely that the axial sections analyzed extended into this region, and when septal perfusion in these patients was compared with that of infants who had intact septa, there was no difference at any level of imaging within the ventricular septum. One of the infants in group I underwent an arterial switch procedure for dextrotransposition of the great arteries. Although the potential exists for coronary artery obstruction after this operation, few patients have clinically apparent postoperative impairment in coronary flow. Tanel and colleagues ${ }^{15}$ reviewed postoperative angiograms performed on 366 healthy patients who underwent the arterial switch operation for transposition of the great arteries. Only 13 patients (3\%)

*Gore-Tex patch, registered trade name of W. L. Gore \& Associates, Inc., Newark, Del. had abnormalities of their coronary arteries by angiography.

Second, these infants had undergone cardiac operations and cardiopulmonary bypass, which have been related to acute myocardial and vascular dysfunction. Ischemia during aortic crossclamping, ${ }^{16}$ inadequate myocardial protection with hypothermia and cardioplegic solutions, ${ }^{17}$ and reperfusion injury ${ }^{18,19}$ may all contribute to acute myocyte dysfunction after cardiac operations. This has direct implications for this study because retention of nitrogen 13-labeled ammonia in myocardium represents a combination of delivery (coronary flow) and metabolic incorporation. However, except for the clinical entity of "stunned myocardium," in which depressed myocardial function is apparent clinically and often protracted, the metabolic and functional alterations associated with cardiopulmonary bypass are transient and have been demonstrated to be reversible within 48 hours after the operation. ${ }^{20-22}$ Our patients all exhibited good cardiac function after their operations and were studied well beyond 48 hours, making it unlikely that cardiopulmonary bypass influenced our results. Endothelial dysfunction has also been demonstrated after cardiopulmonary bypass and could potentially affect both resting flows and the vascular response to adenosine. ${ }^{23,24}$ It is unclear whether this factor could have played a significant role in our studies.

A third consideration relates to the use of adenosine as a coronary vasodilator. This nucleotide activates specific receptors on endothelial and smooth muscle cell membranes in the coronary circulation to cause vasodilation. ${ }^{25}$ Although doseresponse testing has determined that approximately $140 \mu \mathrm{g} / \mathrm{kg} / \mathrm{min}$ is the optimal dose for maximal coronary dilatation in adults, ${ }^{8}$ similar studies have not been performed in infants. It is therefore possible that the dose used in this study did not maximally dilate the coronary vessels in our infants. Unfortunately, because the difficult task of inhibiting patient movement limits the time available for 


\begin{tabular}{cccc}
\hline \multicolumn{4}{c}{ Reserve } \\
\cline { 2 - 4 } & 2 & 3 & 4 \\
\hline 1 & $1.42 \pm 0.30$ & $1.58 \pm 0.30$ & $1.62 \pm 0.43$ \\
$1.48 \pm 0.32$ & $1.65 \pm 0.39$ & $1.96 \pm 0.22$ & $1.61 \pm 0.52$ \\
\hline
\end{tabular}

study, the development of a full dose-response curve for adenosine would be difficult or impossible with spontaneously breathing infants. It is also possible that the vasodilatory response to adenosine may be incompletely developed in the neonatal period, making an adenosine infusion inappropriate to determine myocardial flow reserve in infants.

Finally, at least some of the patients in group I may have had left ventricular hypertrophy as a result of volume or pressure overload. Myocardial hypertrophy can reduce coronary flow reserve, which may also account for the reduced reserve in these patients relative to healthy adults. It should be noted, however, that the immature heart appears to maintain myocardial flow reserve with hypertrophy better than does the adult heart, ${ }^{14}$ which tends to militate against myocardial hypertrophy as an explanation for reduced coronary flow reserve in these infants.

We also investigated myocardial flow in a group of infants whose anatomy and physiology may predispose them toward limited myocardial perfusion. Our findings suggest that infants with HLHS after Norwood palliation have less resting and maximal flow (and oxygen delivery) to their systemic ventricle than do infants who have undergone anatomic repair of a heart defect. The diminished myocardial flow at rest is perhaps surprising in light of the fact that the systemic ventricle in infants with HLHS after Norwood palliation performs increased volume work as a result of supporting both the systemic and pulmonary circulations. The baseline heart rates were nearly identical for each group $(130 \pm 11$ vs $128 \pm 13$ beats $/ \mathrm{min}, p=0.9)$, indicating that a reduction in diastolic perfusion time was not a significant factor. It is possible that the difference in resting flows between the two groups relates to disproportionate flow to the diminutive yet hypertrophied left ventricle of patients with HLHS. Although the left ventricle performs no useful work, it continues to consume significant coronary artery flow, as demonstrated by intense tracer uptake in Fig. 2, B. It is also possible that total coronary artery flow is limited by the anatomy of the neoaorta and that flow to the left ventricle, in effect, "steals" coronary flow from the right ventricular myocardium. Another possible explanation for the diminished coronary flow in the group II patients is that intrinsic abnormalities of the coronary arteries are responsible for the reduction in both resting and maximal coronary flow seen in group II relative to group I patients. Several investigators have described an increased prevalence of coronary-cameral communications in patients with HLHS, especially those with mitral hypoplasia and aortic atresia. ${ }^{26,27}$ No coronary-cameral communications could be appreciated by color-Doppler imaging in any of our patients, although this technique is probably an insensitive method of detecting small sinusoidal communications. In a histologic study of the coronary vessels, Sauer and colleagues ${ }^{28}$ described fibroelastic thickening of the intima with fragmentation and duplication of the internal elastic lamina in nine of 26 patients with HLHS. All but one of these patients had mitral hypoplasia and aortic atresia, suggesting that this subgroup of patients may be at higher risk for impaired myocardial perfusion. Also worth considering is the fact that coronary flow is influenced by arterial oxygen saturation and hemoglobin concentration. ${ }^{14}$ It is difficult to estimate the net impact of these factors on the differential between group I and II myocardial flows. Group II patients had higher resting hematocrits than those in group I (which would tend to reduce flow) but lower arterial saturations (which would tend to increase myocardial flow). Finally, with the vasodilator adenosine, systemic diastolic pressure fell to $31 \mathrm{~mm} \mathrm{Hg}$ in group II patients, which may be at or near the level where coronary perfusion becomes pressure dependent. If so, coronary blood flow with adenosine in the patients with HLHS may have been limited in part because of reduced driving pressure as a result of the adenosine.

The subject of myocardial perfusion in human infants is becoming more important as medical and surgical advances improve outcome for children with complex structural heart disease. Despite a marked improvement in survival for children with HLHS, ${ }^{7}$ there continue to be unexpected deaths after Norwood palliation. In addition, Schwartz ${ }^{29}$ and colleagues demonstrated an increase in collagen within the right ventricular myocardium of infants with HLHS at autopsy. Limited coronary artery reserve coupled with reduced oxygen delivery to the ventricular myocardium may predispose toward 
ischemic damage, which may be seen acutely as sudden death or as progressive ventricular fibrosis and dysfunction. Further studies with PET imaging of myocardial perfusion should provide a broader understanding of myocardial perfusion in patients with HLHS and other types of structural heart disease.

Anthony Schork, $\mathrm{PhD}$, provided assistance with the statistical analysis. We acknowledge Diane Gaffney, RN, for her assistance with patients during the study.

\section{REFERENCES}

1. Hoffman JIE. A critical review of coronary reserve. Circulation 1987;75:I6-11.

2. Gould K, Kirkeeide R, Buchi M. Coronary flow reserve as a physiologic measure of stenosis severity. J Am Coll Cardiol 1990;15:459-74.

3. Walsh MN, Geltman EM, Steele RL, Kenzora JL, Ludbrook PA, Sobel BE, et al. Augmented myocardial perfusion reserve after coronary angioplasty quantified by positron emission tomography with $\mathrm{H}_{2}{ }^{15} \mathrm{O}$. J Am Coll Cardiol 1990;15:11927.

4. Chan SY, Brunken RC, Czernin J, Porent G, Kuhle W, Krivokapich J, et al. Comparison of maximal myocardial blood flow during adenosine infusion with that of intravenous dipyridamole in normal men. J Am Coll Cardiol 1992;20:97985.

5. Hutchins GD, Schwaiger M, Rosenspire KC, Krivokapich J, Schelbert H, Kuhl DE. Noninvasive quantification of regional blood flow in the human heart using N-13 ammonia and dynamic positron emission tomographic imaging. J Am Coll Cardiol 1990;15:1032-42.

6. Fisher DJ, Heymann MA, Rudolph AM. Effects of hemorrhage on myocardial consumption of oxygen and carbohydrate in fetal sheep in utero. J Dev Physiol 1980;2:151-9.

7. Iannettoni MD, Bove EL, Mosca RS, Lupinetti FM, Dorostkar PC, Ludomirsky A, et al. Improving results with firststage palliation for hypoplastic left-heart syndrome. J Thorac Cardiovasc Surg 1994;107:934-40.

8. Wilson RF, Wyche K, Christiansen BV, Zimmer S, Laxson DD. Effects of adenosine on human coronary arterial circulation. Circulation 1990;82:1595-606.

9. Schrader BJ, Inbar S, Kauffman L, Vestal RE, Rich S. Comparison of the effects of adenosine and nifedipine in pulmonary hypertension. J Am Coll Cardiol 1992;19:1060-4.

10. Haywood GA, Sneddon JF, Bashir Y, Jennison SH, Gray $\mathrm{HH}$, McKenna WJ. Adenosine infusion for the reversal of pulmonary vasoconstriction in biventricular failure. Circulation 1992;86;896-902.

11. Muzik O, Beanlands R, Wolfe E, Hutchins GD, Schwaiger M. Automated region definition for cardiac nitrogen-13ammonia PET imaging. J Nucl Med 1990;34:336-44.

12. Schwaiger M, Muzik O. Assessment of myocardial perfusion by positron emission tomography. Am J Cardiol 1991;67: 35D-43D.

13. Krivokapich J, Smith GT, Huang SC, Hoffman EF, Ratib O, Phelps ME, et al. ${ }^{13} \mathrm{~N}$ ammonia myocardial imaging at rest and with exercise in normal volunteers: quantification of absolute myocardial perfusion with dynamic positron emission tomography. Circulation 1989:80:1328-37.

14. Hoffman JIE. Pediatric cardiovascular intensive care: myocardial perfusion. Prog Pediatr Cardiol 1995;4:117-23.

15. Tanel RE, Wemovsky G, Landzberg MJ, Perry SB, Burke AP. Coronary artery abnormalities detected at cardiac catheterization following the arterial switch operation for transposition of the great arteries. Am J Cardiol 1995;76:153-7.

16. Gold JP, Roberts AJ, Hoover EL, Blank S, Gay WA, Subramanian VA. Effects of prolonged aortic cross clamping with potassium cardioplegia on myocardial contractility in man. Surg Forum 1979;30:252-4.

17. Swanson DK, Myerowitz PD. Effect of reperfusion temperature and pressure on the functional and metabolic recovery of preserved hearts. J Thorac Cardiovasc Surg 1983;86:24251.

18. Przyklenk K, Kloner RA. "Reperfusion injury" by oxygenderived free radicals? Circ Res 1989;64:86-96.

19. Opie LH. Reperfusion injury and its pharmacologic modification. Circulation 1989;80:1049-62.

20. Gray R, Maddahi J, Berman D, Raymond M, Waxman A, Ganz W, et al. Scintigraphic and hemodynamic demonstration of transient left ventricular dysfunction immediately after uncomplicated coronary artery bypass grafting. J Thorac Cardiovasc Surg 1979;77:504-10.

21. Phillips HR, Carter JE, Okada RD, Levine FH, Boucher CA, Osbakken M, et al. Serial changes in left ventricular ejection fraction in the early hours after aortocoronary bypass grafting. Chest 1983;83:28-34.

22. Mangano DT. Biventricular function after myocardial revascularization in humans: deterioration and recovery patterns during the first 24 hours. Anesthesiology 1985;62:571-7.

23. Tsao PS, Aoki N, Lefer DJ, Johnson G, Lefer AM. Time course of endothelial dysfunction and myocardial injury during myocardial ischemia and reperfusion in the cat. Circulation 1990;82:1402-12.

24. Tsao PS, Lefer AM. Time course and mechanism of endothelial dysfunction in isolated ischemic- and hypoxic-perfused rat hearts. Am J Physiol 1990;259:H1660-6.

25. Olsson RA, Davis CJ, Khouri EM, Patterson RE. Evidence for an adenosine receptor on the surface of dog coronary myocytes. Circ Res 1976;39:93-8.

26. O'Connor WN, Cash JB, Cottrill CM, Johnson GL, Noonan JA. Ventriculocoronary connections in hypoplastic left hearts: an autopsy microscopic study. Circulation 1982;66: 1078-86.

27. Baffa MJ, Chen SL, Guttenberg ME, Norwood WI, Weinberg PM. Coronary artery abnormalities and right ventricular histology in hypoplastic left heart syndrome. J Am Coll Cardiol 1992;20:350-8.

28. Sauer U, Gittenberger-de Groot AC, Geishauser M, Babic R, Buhlmeyer K. Coronary arteries in the hypoplastic left heart syndrome: histopathologic and histometrical studies and implications for surgery. Circulation 1989;80:I168-76.

29. Schwartz SM, Gordon D, Mosca RS, Bove EL, Heidelberger KP, Kulik TJ. Collagen content in normal, pressure and pressure-volume overloaded developing hearts. Am J Cardiol 1996;77:734-8. 